\title{
Tarihi Dokuda Çağdaş Kültürr Yapısının Görsel Etki Değerlendirmesi: Odunpazarı Modern Müze Örneklem Alanı
}

\author{
Gözde Kızılkan ${ }^{1}$ \\ ORCID: 0000-0002-9042-4696
}

\author{
Ömer Yeşildal ${ }^{2}$ \\ ORCID: 0000-0001-8478-9405
}

Öz

Bu çalışmada; tarihi bir kent dokusu içinde projelendirilmiş yeni bir kültürel yapının, bulunduğu kentsel çevredeki görsel etkisinin insan-çevre ilişkileri üzerinden değgerlendirilmesi amaçlanmıştır. Literatür taramast ile görsel etki çözümlemesi üzerine kavramsal çerçevenin oluşturulması sonrasında, tarihi bir kentsel bağlam içinde inşa edilen modern bir yapı çalışma/örneklem alanı olarak seçilmiştir. Araştırma, mimari uyaranın insan-çeore etkileşiminde görsel etki değerlendirilmesine odaklanırken; anket sorgulamast tekniğgi aracilığıyla katılımciların demografik özelliklerine yönelik bilgi ve görüşlerini toparlama, değerlendirme ve bir sonuç ortaya koyma üzerine şekillenmektedir. Bu bağlamda; çalışma sorusu olarak farklı sosyo-demografik özelliklere sahip bireylerce tarihi kent alan içinde konumlanan çă̆daş bir yapının görsel etki değerlendirilmesinin hangi faktörlere göre anlamlandırlddı̆̆ının saptanması hedeflenmekte; ilerisi için yol gösterici olabilecek ipuçlar ortaya konmaktadır.

Anahtar Kelimeler: görsel etki değerlendirme; insan-çevre ilişkileri; çeorenin algilanmasl; görsel çeore tasarmi; tarihi kent dokusu.

\footnotetext{
${ }^{1}$ Doktora öğrencisi, Yıldız Teknik Üniversitesi, E-mail: kizilkangozde@yahoo.com

2 Doktora öğrencisi, Ylldız Teknik Üniversitesi, E-mail: omeryesildall@gmail.com

idealkent @ C Kent Araştırmaları Dergisi (Journal of Urban Studies) 


\title{
Visual Impact Evaluation of a Contemporary Build- ing in a Historical Pattern: Odunpazarı Modern Museum Sampling Area
}

\author{
Gözde Kizılkan ${ }^{3}$ \\ ORCID: 0000-0002-9042-4696
}

\author{
Ömer Yeşildal 4 \\ ORCID: 0000-0001-8478-9405
}

\begin{abstract}
In this study, it is aimed to evaluate the visual impact of a new cultural building, erected in a historical urban pattern, through human-environment relations. After establishing the conceptual framework of the visual impact research upon the literature review, a modern building in a historical urban context was chosen as the field of study/sampling area. The study is focused on the visual impact evaluation of the architectural stimuli through the human-environment interactions and is shaped by collecting and assessing the demographic characteristics and opinions of the respondents through the surveying (questionnaire) technique to reveal a conclusion. In this context, it is aimed to determine which factors are received as meaningful by individuals with different socio-demographic characteristics while evaluating the visual impact of a contemporary building located in a historical urban area; and it is also presented some useful clues that will be instructive for the future studies.
\end{abstract}

Keywords: visual impact evaluation; human-environment relations; perception of environment; visual environment design; historical urban pattern.

\footnotetext{
${ }^{3}$ Doctorand, Yıldız Technical University, E-mail: kizilkangozde@yahoo.com

${ }^{4}$ Doctorand, Yıldız Technical University, E-mail: omeryesildall@gmail.com

idealkent @ C Kent Araştırmaları Dergisi (Journal of Urban Studies) 


\section{Giriş}

Çevre; doğal ve yapay öğelerden meydana gelen, varlıkların ilişki süreçleri içinde etkileşimde olduğu uzamsal/zamansal ortamdır. Mimari çevre; fiziksel mekân ile sosyal mekân arasındaki dengeyi amaçlayan, insançevre ilişkileri temelinde araştırmalar ortaya koyulmasına ve insan davranışlarını bağlantılar aracılığıyla yorumlamaya çalışan modeller geliştirilmesine olanak tanıyan yaşam alanlarıdır (Polatoğlu, 2012). Mimari tasarım, çeşitli düzlemlerde yaşanan küresel dönüşümlerin anlam bulduğu devimsel bir olgudur. Bünyesinde barındırmakta olduğu öznel-bireysel deneyim ile nesnel-kuramsal ve kavramsal bilgi birikimleri sonucunda yenilikçi şekilde anlama ve yorumlama becerileri geliştirmekte, disiplinler arası bir bakış açısı sunmakta ve estetik, ideolojik gibi farklı yaklaşımlar ortaya koymaktadır (Düzgün Bekdaş ve Yıldız, 2018).

Çevrenin algılanması, bilinmesi ve yorumlanması; duyu organları aracılığıyla hissedilerek algılanış biçimleri üzerinden çevresel niteliklerin tanımlanması ile tercih yapma, karar verme ve uygulama sürecinin bütünüdür (Rapoport, 1982). Bireyin, çevreden aldığı duyumlar ağılıklı olarak görsel uyaranlar aracılığıyla gerçekleşmektedir (Aksoy, 1975). Fiziksel mekândaki estetik tercihlerin sosyo-demografik ve kültürel etkilerle şekillenebildiği, uzman görüşleri ile desteklenen pek çok çalışmanın da temelini oluşturmaktadır. Şimdiye kadar yapılan çeşitli araştırma ve çalışmalar; mimar/planc//tasarımcıların görsel etki üzerindeki tercihlerinin, profesyonel olarak bu alanlarda eğitim almamış kişilerden belirgin şekilde farklılıklar içerdiğini göstermektedir (Janssens 1984; Sanoff, 1991; Polatoğlu, 1994; Rasmussen, 1994; Groat ve Wang, 2013 vb.).

Şehirlerin görünümü; projelerin tasarlanma, inşa edilme ve kullanım biçimlerini etkileyen dinamik faktörler üzerinden büyük değişimlere maruz kalmaktadır. Hoş olarak nitelenen mekânların görsel özelliklerinin; belirgin ve okunaklı, anlamsal zenginlik ve çeşitlilik içeren ortamlar sunduğu, yapılan pek çok araştırmanın konusu olmakta ve ileriye dönük sonuçlar ortaya koymaktadır.

Tarihi kent dokusu; geçmiş dönemlerin fiziksel ve sosyo-kültürel yap1larını, yaşam biçimlerini, insan-çevre ilişkilerini yansıtan hafıza mekânlarıdır. Dolayısıyla, kentsel belleği oluşturan bu özel alanlar bilinçli ve uyumlu tasarımlar, işlevler ve değerlendirme süreçleri ile bütüncül olarak ele alınmalıdırlar. Genel kabul, çağdaş şehirlerin koruma bağlamında evrensel standartlara ulaşmada yetersiz kaldığı ve dönüşüm süreçlerinde 
stratejik mekânsal/işlevsel planlama yaklaşımlarındaki eksikliklerin bu dönüşümlerdeki sorunların sebepleri olabileceği yönündedir (Özcan, 2009). Başarısız olarak nitelenen tarihi kent dokusu müdahaleleriyle ilgili görüşler, genellikle uzmanlar tarafından dile getirilir; ancak uzman olma-

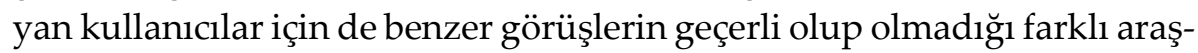
tırma sorularını akıllara getirmektedir.

Bu çalışmanın amacı; tarihi kentsel doku içinde inşa edilen çağdaş bir yapının görsel etki değerlendirilmesine odaklanırken, katılımcıların demografik karakteristiklerine yönelik görüşlerini toparlama, değerlendirme ve bir sonuç ortaya koyma üzerine şekillenmektedir. Bu bağlamda; çalışma sorusu olarak farklı sosyo-demografik özelliklere sahip bireylerce tarihi kent alanı içinde konumlanan modern bir kültürel yapının görsel etki değerlendirilmesinin, hangi faktörlere göre anlamlandırıldığının saptanması ve yorumlanması hedeflenmektedir.

Çalışma alanı olarak seçilen mimari uyaran hakkında hem yerel hem de ulusal bağlamda tasarım ve mimarlık camiasına yön veren olumlu ve olumsuz görüşler bulunmaktadır. Çalışmanın amacı, uluslararası bir tasarım ekibi tarafından tarihi kent dokusu içinde projelendirilmiş modern bir kültürel yapının, kullanıcıları tarafından nasıl anlamlandırıldığını ölçmek; yapının görsel etkisinin, mimarlık/inşaat/tasarım sektörü ve diğer meslek gruplarında çalışan bireyler tarafından nasıl değerlendirildiğini ortaya koymaktır. Bu sebeple; gerçek ortamdaki kent kullanıcılarının örneklem alanındaki görsel etki odaklı değerlendirmelerini analiz ederek irdelemek, ileride yapılacak olan yeni projeler için birtakım ölçütler ortaya konmasina olanak tanıyacaktır.

\section{Yöntem}

Çalışmanın yönteminde kullanılan soru-cevap sistemi yardımıyla çevreye gösterilen anlamsal tepkileri ölçmek için anlamsal farklılaşma ve anlamsal sıralama teknikleri ile benzerlik gösteren 5'li aralıktaki soru-cevap sistemi kurgulanmıştır. Sistemde, Bishop'ın (1977) CRIG Analizi ve Polatoğlu'nun (1994) deneysel çalışmasındaki yöntemler yol gösterici olmuştur. Farklı kutuplardaki sıfat çiftleri yerine; araştırma konusunun özelliklerine uygun sıfatlarla tanımlanan sorular üzerinden 5'li aralıktaki her bir değişkene verilen sıralama ölçekli yanıtlar ile çalışma alanı olarak seçilen uyaranın görsel etki değerlendirmesinde, ortalamalar alınarak sonuçlar belirlenmiştir. Çevresel elemanların bütüncül ve tanımlayıcı boyutları için 
faktör gruplarından yararlanılmıştır. Görsel çevreye yaklaşımların ölçülmesi için faktörlerin geliştirilmesinde; Osgood vd., (1975), Küller (1973), Sanoff (1974), Sorte (1975), Krampen vd. (1978), Smardon vd. (1986), Hershberger ve Cass (1988), Nasar (1989) ve Zeisel (1995)'ın çalışmalarından yararlanılmıştır. Faktör grupları aşağıda belirtildiği şekilde kategorileştirilmiş ve detaylandırılmıştır:

Genel değerlendirme (hoş, uyumlu, olumlu)

Kütle (güçlü, kaba)

Biçim (karmaşık, kapalı, tekdüze)

Yüzey özelliği / doku (malzeme uygunluğu, renk uygunluğu)

Ölçek (geniş [iri], yüksek)

Etki (ilginç, yeni, belirgin)

Yaş, cinsiyet, meslek gruplarına yönelik genel katılımcı profilini belirlemek için yöneltilen kapalı uçlu sorular ile demografik karakteristik ortaya konmuştur. Çalışma alanı hakkında sorulan açık uçlu 2 adet soru ile genel tanımlamalar ile ilgili bilgi toplanmıştır. Sonrasında, toplamda 15 adet soru içeren 5'li aralıkta sıralanan açıklamalar alt alta düzenlenerek çalışma alanı hakkında görsel etki faktörleri değerlendirilmesi yapılmış ve son olarak da açık uçlu 2 adet soru ile katılımcıların çalışma alanındaki kent kimliği temalı yorumları belirlenmiştir. Sorgulama sonrası elde edilen veriler, karşılaştırma tekniği kullanılarak grafikler yardımıyla analiz edilmiş ve binanın görsel etki çözümlemesinin yapılabilmesi için bir sentez ortaya konarak sonuca varılmıştır.

\section{Görsel Etki Değerlendirmede Kavramsal Çerçeve}

Görsel etki değerlendirme araştırmaları; bir yere ait görsel nitelikleri, mekânsal organizasyonu, göz ile algılanan duyumlar ön planda olmak üzere birbirleriyle işlevsel bir etkileşim üzerinden yorumlamaya olanak tanıyan çalışmalar bütünüdür (Palmer, 2000). Görsellik; doku, renk, biçim gibi estetik elemanlardan oluşan özelliklerin yanında; fiziksel mekân ile kurduğu uyum, tekrar, ritim, hiyerarşi, doluluk-boşluk gibi ilkeler üzerinden ifade edilen olgularla şekillenmekte ve nihayetinde bütün bu ayırıcı niteliklerin bir değerlendirme çalışması üzerinden ölçülmesi ile görsel etkiler açığa çıkartılmaktadır.

Yapılı çevrenin insan üzerinde yaratmış olduğu duyulanım ve alg1lama bağlamları, nesnelerin görsel nitelikleri ve insanlar tarafından nasıl anlamlandırıldıkları mevcut ve gelecek projelerin etki çözümlemelerini 
yapmak ve bilimsel veriler ortaya koyabilmek adına önemle üzerinde durulan araştırma alanlarındandır.

Görsel etki değerlendirmesi çalışmalarında; nesnelerin görsel niteliklerinin bireyler ve toplumlar üzerindeki etkileşim düzeylerinin farklı boyutlar üzerinden (kültürel, tarihsel, sosyolojik, psikolojik, demografik vb.) tanımlanması, disiplinler arası bir yaklaşım gözetilerek insan bilimlerinin sunduğu tekniklerden de yararlanarak algılama, anlamlandırma ve davranışlara etki eden gerekli ilişkilerin kurgulanarak araştırılması önem kazanmaktadır (Lozano, 1988).

Yapılı çevredeki fiziksel strüktürler; belirli nitelikleri, kullanım değerleri, kent dokusuna eklemlenmesi ve görülebilirliği, erişilebilirliği, algılayan kişi üzerinde bırakmış olduğu izlenim ve çağrışımlar gibi pek çok değişken üzerinden deneyimlenmektedir. Yapılı çevre kullanıcıları ile belli kavramsal çerçeveler (konfor düzeyi, memnuniyet düzeyi, algisal yarar düzeyi vb.) içinde yapılan sorgulamalarda çeşitli yaş grupları, meslek grupları, eğitim seviyeleri, sosyo-demografik özelliklerin farklılaşmakta olduğu görülmektedir (Aydınlı, 1992). Darçın'ın (2012) desenlerin görsel etki değerlendirmesi üzerine yapmış olduğu gerçek mekân simülasyonlu deneyinde, pek çok araştırmacının önceki çalışmalarına gönderme yapılarak; yapılı çevrenin farklı özellikteki kişilerce hoşnutluk, uygunluk, konfor düzeyi vb. duyguları uyandırdığı ve böylelikle davranışlar ve kararların verilmekte olduğu sonucuna varılmaktadır.

Zeisel (1995), çevre-davranış araştırmalarının planlama kurgularının üç adımdan oluştuğunu belirtmektedir. Bunlar; araştırma yaklaşımı, araştırma tasarımı ve araştırma ortamı olarak gruplanmaktadır. Tarihi bir kentsel doku içindeki çağdaş bir yeni yapı olan çalışma alanı seçimi ile görsel etki değerlendirme verileri anket sorgulaması tekniği ile toplanmış; veri analizi ise öznel ölçümler sonucunda yorumlanmıştır. Özellikle mimari bir uyarana karşı verilen tepkileri ölçmekte yaygın olarak kullanılan anlamsal farklılaşma tekniğine yönelik pek çok niteliğin tek seferde değerlendirilebilmesi için Osgood vd. (1975), Küller (1973) ve Sorte (1975)'nin çalışmalarında belirtilen faktör grupları ve değişkenler kategorize edilip anket taslağının kavramsal çerçevesi oluşturulmuştur. 


\section{Çalışma / Örneklem Alanı}

\section{Odunpazarı, Eskişehir}

Eskişehir'in kentsel gelişiminin temelini şehrin güneyindeki tepe üzerinde kurulmuş olan Odunpazarı semti oluşturmaktadır. Semt, Osmanlı sivil mimari yapıları ve sit alanına giren ahşap evleriyle günümüze kadar bozulmadan gelebilmiş nadir alanlardandır. Odunpazarı'ndaki tarihi doku, geçmişle günümüz arasında köprü görevi üstlenmektedir. Bölgede birçok sivil ve dini mimari yapı bir arada bulunmaktadır. Tarihi Odunpazarı Evleri, bölgenin topografik yapısına uygun olarak sokak ve arazinin coğrafi konumuna uyumlu bir şekilde yerleşmişlerdir (Şekil 1).

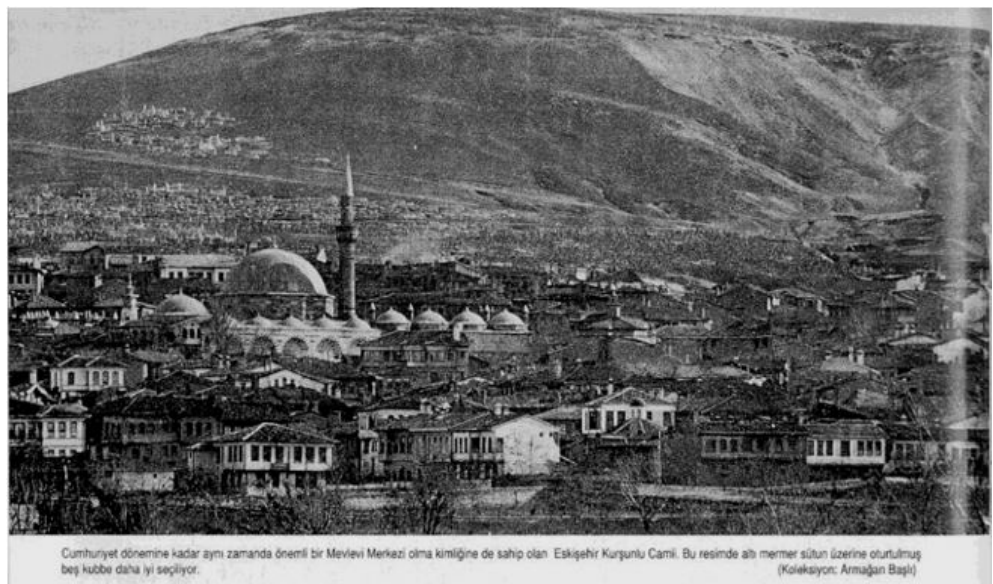

Şekil 1. Eskişehir Büyükşehir Belediyesi arşivi, Odunpazarı Banaz, F. (2017).

Evler, Anadolu-Türk kentinin geleneksel dokusunu yansıtmaktadır. Dar sokaklar boyunca bitişik nizam yapılmış olan 1, 2 ve 3 katlı evler çoğunlukla sokağa açılır. Evlerin alt katları kiler, depo, kömürlük, ambar olarak kullanılırken, cepheleri ya sağır bırakılmış ya da küçük pencerelerle hareketlendirilmiştir. Yaşam alanı olarak kullanılan üst katlarda ise; sokakla iletişimi sağlamak amacıyla cepheler çıkmalarla bütünleşmektedir. Çıkmalar; sokağın yapısına, arsanın şekline göre üst katlarda geniş yaşam alanları oluşturabilmek, baş odayı diş cephede vurgulayabilmek, evin sokakla ve dış dünyayla iletişimini sağlayabilmek için özenle biçimlendirilmişlerdir.

Odunpazarı, eski bir yerleşim yeri olmakla birlikte bugün kullanılan kentsel alanları cumhuriyetin ilanından sonraki dönemlerde merkez bölge olarak işlev kazanmış ve modernleşme hareketleriyle birlikte yeni 
bir dönüşüm anlayışı benimsenmiştir. Küreselleşmenin de etkisiyle çağdaş kent nitelikleri edinme sürecine girmiştir.

\section{Odunpazarn Modern Müze (OMM)}

Eskişehir kentinin Odunpazarı ilçesinde 2019 senesinin Eylül ayında açılan Odunpazarı Modern Müze (OMM), kentin gelişmekte olan merkez bölgesinde yer almaktadır. UNESCO Dünya Kültür Mirası Geçici Listesi'ne girmeye hak kazanan geleneksel Osmanlı ahşap konut yapılarının kümelendiği tarihi bölge ile iç içe geçen tepe konumda, kültürlerarası bir etkileşimi teşvik etmesi planlanarak Japon mimar Kengo Kuma ve ekibi (KKAA) tarafından projelendirilmiştir (Şekil 2). Bölgenin tarihi kent dokusu ve kültürel mirasını tasarıma yansıtmayı amaçlayan proje ekibi ile yapılan pek çok röportajda, özel olarak imal edilen ahşap diş kaplama malzemeleri ile çevrelenmiş müze binasının modern görünümü sayesinde bölgedeki geleneksel sokak dokusunu destekleyen yeni bir odak noktası yaratılmasının amaçlandığı belirtilmektedir. Özellikle diş cephe ve iç mekânda kullanılan ahşap lata malzeme, bölgenin adı ile anılan tarihi belleğine bir gönderme olmasının yanında, sürdürülebilirlik ölçütleri bağlamında tasarımı ön plana alan bir yaklaşım sunmaktadır.

Kengo Kuma \& Associates ortaklarından ve projenin yürütücüsü Yuki Ikeguchi, kendisi ile yapılan bir söyleşide müze binasının tasarımı ve etkileri ile ilgili şu yorumları yapmaktadır: "Odun, kentin mirasında önemli bir yere sahip. Etrafina konfor ve sıcak bir atmosfer sunan ahşap ile inşa etmek, dolayısıyla bizim önceliğimiz olmuştur. Toplum ve sanat arasında bir bă̆ kurma amacı, bu projenin en başından beri kalbidir. Kendi içinde farklı deneyimler yaratan Odunpazarı sokak dokusu ve insan ölçeğini merkeze alan binanın, kent tarihi ve hafizasını taşıyan misyonu ile bir nirengi noktası olmasını istedik. OMM binası, kentin ve Anadolu coğrafyasının geniş kesimlerine ilham kaynağı olacaktır." (“Designboom", 2019). 

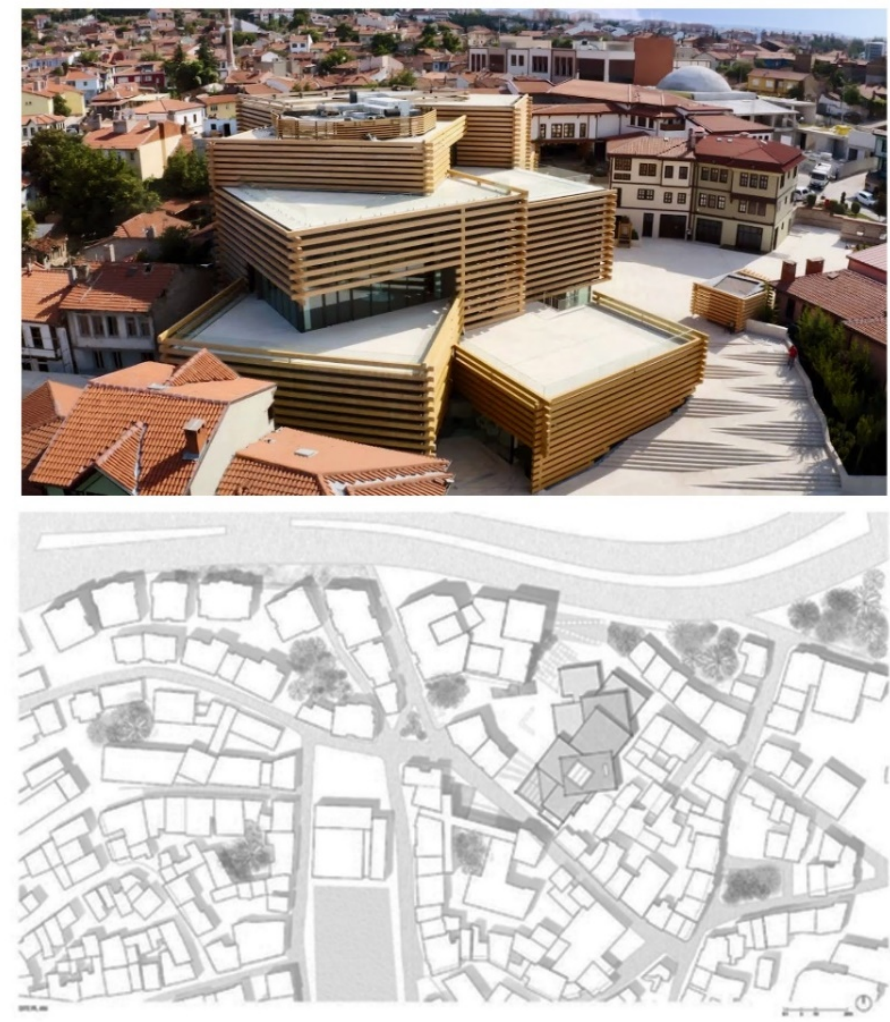

Şekil 2. Kuzey cephesinden drone çekimi (üstteki) / Vaziyet planı (alttaki) (Kolaj, yazarlar tarafından oluşturulmuştur.)

Binanın, hem tasarım süreci ve aktörleri hem içinde bulunduğu tarihi çevre ile bütünleşmesi (Şekil 3) hem de iç mekânlarında sergilenmekte olan çağdaş sanat eserleri dolayısıyla kullanıcılarına çok yönlü bir deneyim yaşatmakta olduğu gözlemlenebilmektedir. Bina; uluslararası mecralarda yankı uyandıran tasarımcıları, projelendirme ve inşa sırasında güdülen sürdürülebilirlik kaygıları ve Eskişehir'in tarihi kentsel dokusu içinde yer alması ile Türkiye'yi -bilinen büyükşehirleri haricinde- tasarım, mimarlık ve şehircilik platformlarında çeşitlilik sunan, etkili bir tartışma düzlemine taşımaktadır. Yapının konumu, tasarım kararları, kentsel doku ile ilişkisi gibi fiziksel mekâna etkileri haricinde; kullanıcılar üzerinde oluşturduğu farklı his ve duygular dolayısıyla da bulunduğu alandaki sosyal mekâna önemli katkılar sağlamaktadır. 


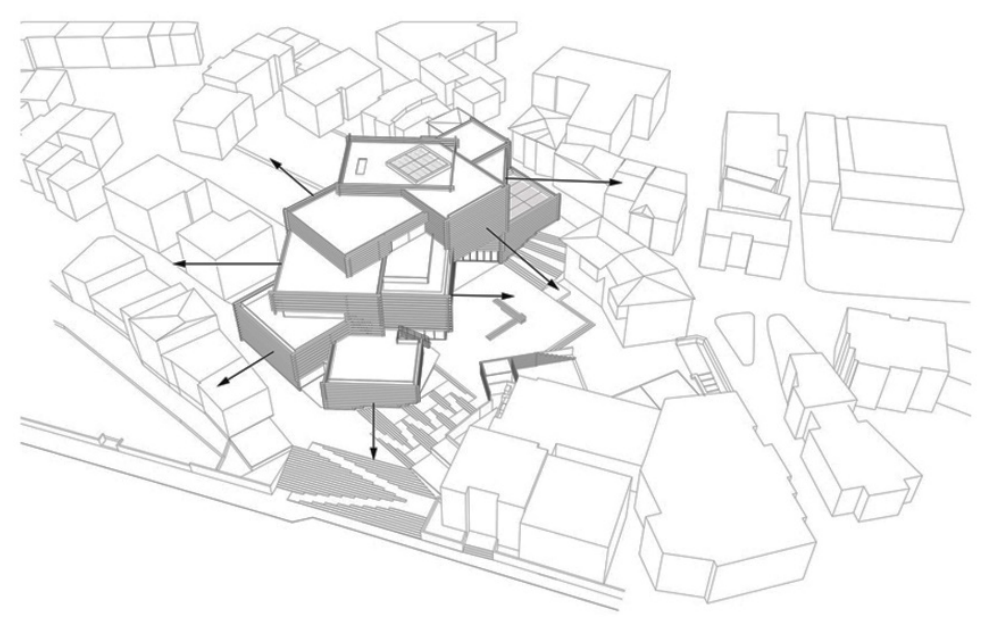

Şekil 3. Yönelim Diyagramı(Arkitektuel, t.y)

\section{Bulgular ve Değerlendirmeler}

Ahşap konut mimarisi ağırlıklı ve kısmen şehir içinde bulunan tarihi dokudaki çalışma alanı olarak seçilen yeni ve modern kültürel yapının görsel etki değerlendirmesini ölçmek için ankete katılan 50 kişinin, öznel yarg1larının niceliksel olarak bilimsel temelde şekillendirilebilmesi için yapıyı ziyaret etmiş olmaları şartı aranmıştır.

2019 yılının Aralık ayı içinde internet üzerinden uygulanan anket çalı̧̧masında, görsel etki değerlendirme faktörlerinin belirlenebilmesine imkân tanıyan ve uygun sıfatlarla oluşturulan sorular yöneltilmiş; yapının görsel etkisinin, bulunmakta olduğu çevresel doku ile ilişkisinin incelenmesi hedeflenmiştir. İlk üç soru demografik özellikleri belirlemek üzere yaş, cinsiyet ve meslek belirlemeye yönelik kapalı uçlu çoktan seçmeli sorulardan oluşturulmuştur. Çalışma alanının görsel etki değerlendirmesi kısmı; öncelikle iki adet açık uçlu soru ile binanın tasarımı ve çevre ile ilişkisi özelinde fikirsel bir değerlendirme ile başlamış, sonrasında da yapının girişinin kolay bulunup bulunmadığı sorulmuştur. Bu şekilde sadece binanın cephe görünüşü değil; iç mekân kurgusu için de daha sonra yapılabilecek olan çalışmalar için pilot soru niteliğinde temel bir soru yöneltilmiştir. Buna göre; bina girişi ziyaretçiler tarafından kolay fark edilebilir bir konumda bulunmamaktadır. Akabinde, 15 adet soru cümleleri ile katılımcıların faktör gruplarına göre kategorileştirilerek 5'li ölçek üzerinden kendilerine en uygun değerlendirmeyi işaretlemeleri talep edilmiştir. 
Yapılan anket çalışmasının katılımcıların fazla vakitlerini almaması için 5'li ölçek tipi seçilmiştir. Son olarak; hazırlanan iki adet açık uçlu soru ile de cephe bütünlüğünün kent kimliği ile olan ilişkisi ve binanın tasar1mını yabancı bir mimarlık ofisinin yapmış olmasının, binanın günümüzdeki popülaritesi üzerinde etkili olup olmadığı sorusu ile görüşlerini belirtmeleri talep edilmiştir.

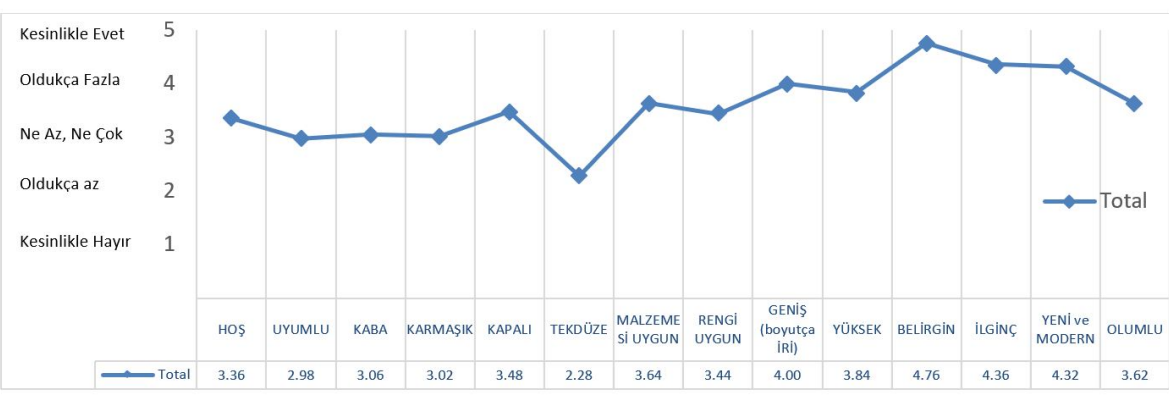

Şekil 4. Görsel etki değerlendirme ifadelerinin bina bütünü için aritmetik ortalama sonuçlarının çizgi grafiği

Yapılan çalışmadaki değişkenleri tek tek ayırmadan önce, binanın görsel etkisinin genel bir değerlendirilmesinin elde edilebilmesi için 50 kişinin vermiş olduğu yanıtların aritmetik ortalaması alınmıştır (Şekil 4). Çalışma alanı olarak seçilen yapının görsel etki değişkenleri özelinde çevresindeki yapılarla birlikte;

' genel değerlendirmesi; hoş, uyumlu ve oldukça fazla olumlu olarak bulunmuştur.

> kütlesel değerlendirmesi; güçlü ve kaba olarak bulunmuştur.

> biçimsel değerlendirmesi; karmaşık, oldukça fazla kapalı ve oldukça az oranda tekdüze bulunmuştur.

> diş cephede kullanılan yüzey elemanlarının uyum değerlendirmesinde; malzemesi oldukça fazla uygun, rengi ise uygun olarak bulunmuştur.

> ölçeği bakımından değerlendirilmesi; oldukça fazla geniş (iri) ve oldukça fazla yüksek bulunmuştur.

$>$ etki değerlendirmesi; oldukça fazla ilginç, oldukça fazla yeni ve modern ve kesinlikle belirgin bulunmuştur. 


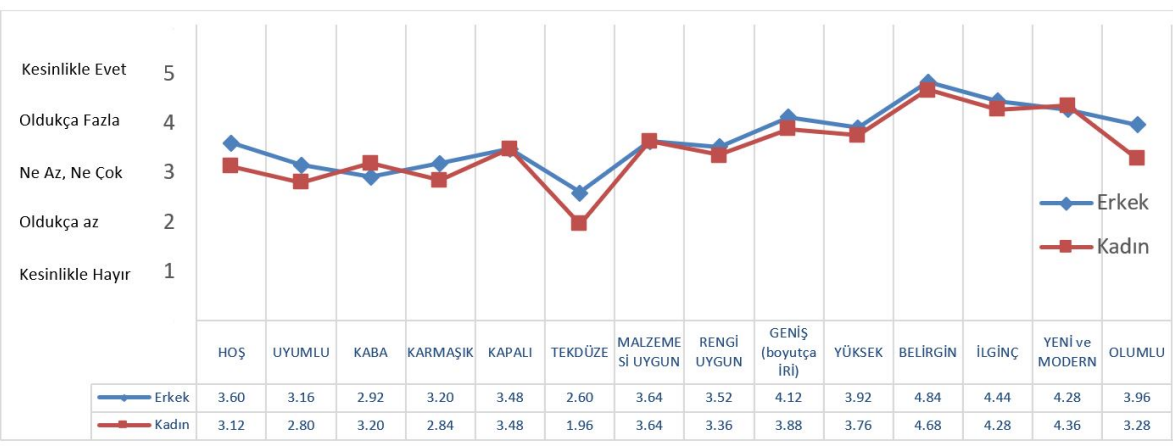

Şekil 5. Görsel etki değerlendirme ifadelerinin aritmetik ortalama sonuçlarının cinsiyet farklılı̆̆ına göre çizgi grafiği

Anketi yanıtlayan 50 kişinin 25'i erkek, 25'i kadın katılımcılardan oluşmaktadır. Görsel etki değerlendirme ifadelerinin cinsiyetlere göre yer yer farklılık göstermekte olduğu görülmektedir. Dikkati çeken iki farklılık noktası da çalışma alanı olarak sorgulanan binanın erkeklere kıyasla, kadınlara göre oldukça az oranda tekdüze; erkekler yapıyı çevresine göre kadınlara oranla oldukça fazla hoş ve oldukça fazla olumlu olarak değerlendirmektedirler (Şekil 5). Buna göre çalışma alanının çevresindeki yapılarla birlikte;

genel değerlendirmesi; erkek ve kadınların her ikisine göre de uyumlu bulunmaktayken; yapı erkeklere göre oldukça fazla hoş ve oldukça fazla olumlu, kadınlara göre ise hoş ve olumlu olarak görülmektedir.

$>$ kütlesel değerlendirmesi; hem kadın hem de erkeklere göre güçlü ve kaba olarak bulunmuştur.

b biçimsel değerlendirmesi; hem kadın hem erkeklere göre karmaşık, oldukça fazla kapalı; kadınlara göre oldukça az oranda tekdüze, erkeklere göre ise tekdüze olarak bulunmuştur.

> diş cephede kullanılan yüzey elemanlarının uyum değerlendirmesinde; hem kadın hem de erkeklere göre malzemesi oldukça fazla oranda uygun; rengi ise kadınlara göre uygun, erkeklere göre oldukça uygun olarak bulunmuştur.

$>$ ölçeği bakımından değerlendirilmesi; hem kadın hem de erkeklere göre oldukça fazla geniş (iri) ve oldukça fazla yüksek bulunmuştur. etki değerlendirmesi; hem kadın hem erkeklere göre oldukça fazla ilginç, oldukça fazla yeni ve modern, hem kadın hem erkeklere göre ise kesinlikle belirgin bulunmuştur. 


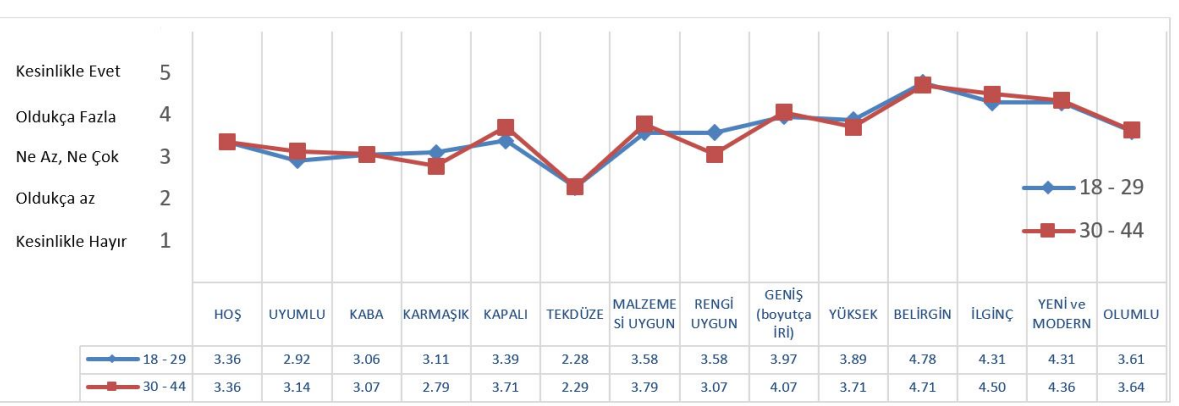

Şekil 6. Görsel etki değerlendirme ifadelerinin aritmetik ortalama sonuçlarının yaş aralığına göre çizgi grafiği

Anketi yanıtlayan 50 kişinin 36'sı (\%72) 18-29 yaş arasında, 14'ü (\%28) 30-44 yaş arasındaki katılımcılardan oluşmaktadır. Görsel etki değerlendirme ifadelerinin yaş farklarına göre ciddi farklılıklar ortaya koymadığ görülmektedir. Dikkati çeken farklılıklar ise biçimsel faktörlerden karmaşıklık ve kapalılık, doku ve yüzey elemanları faktörlerinden renk uygunluğu sorusunda belirginleşmektedir (Şekil 6). Buna göre çalışma alanının çevresindeki yapılarla birlikte;

> genel değerlendirmesi; $18-29$ ve 30-44 yaş aralığına göre oldukça hoş; her iki yaş grubuna göre de uyumlu ve oldukça olumlu olarak bulunmuştur.

> kütlesel değerlendirmesi; her iki yaş grubu için de güçlü ve kaba olarak bulunmuştur.

biçimsel değerlendirmesi; 18-29 yaş aralığına göre karmaşık, 30-44 yaş aralığına göre oldukça az oranda karmaşı; 18-29 yaş aralığına göre kapalı, 30-44 yaş aralığına göre oldukça fazla oranda kapalı; her iki yaş aralığına göre de oldukça az oranda tekdüze bulunmuştur.

> diş cephede kullanılan yüzey elemanlarının uyum değerlendirmesinde; $18-29$ ve 30-44 yaş aralığına göre malzemesi oldukça uygun; 18-29 yaş aralığına göre rengi oldukça fazla oranda uygunken, 3044 yaş aralığına göre ise rengi uygun bulunmuştur.

> ölçeği bakımından değerlendirilmesi; $18-29$ ve 30-44 yaş aralığına göre oldukça fazla geniş (iri) ve oldukça fazla yüksek bulunmuştur.

$>$ etki değerlendirmesi; her iki yaş grubuna göre de oldukça fazla ilginç, oldukça fazla yeni ve modern ve kesinlikle belirgin bulunmuştur. 


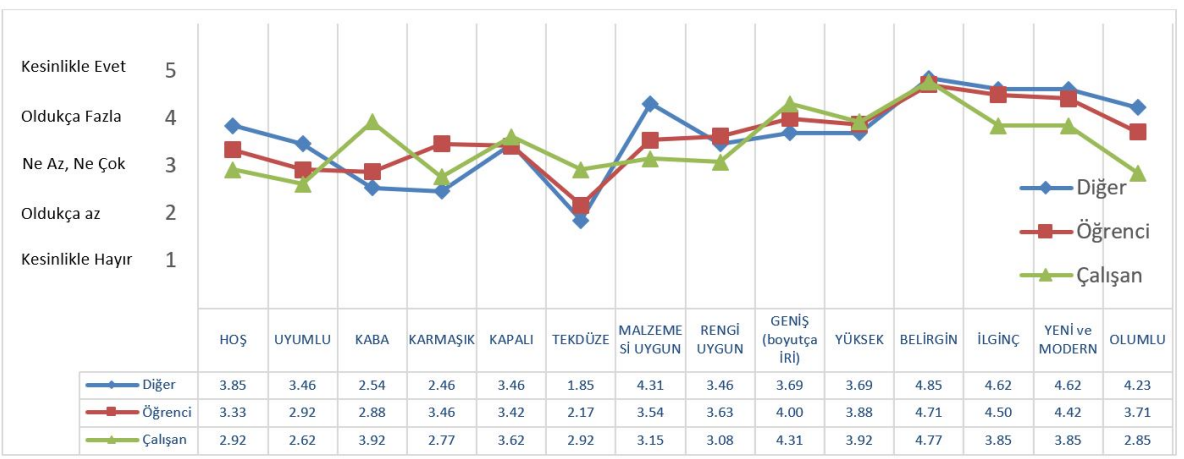

Şekil 7. Görsel etki değerlendirme ifadelerinin aritmetik ortalama sonuçlarının mimarlık/inşaat/tasarım sektörlerinde çalışan, bu sektörlere ait bölümlerde okuyan (öğrenci) ve bu sektördeki meslek gruplarına dahil olmayanlara (diğer) göre çizgi grafiği

Anketi yanıtlayan 50 kişinin 24'ü (\%48) mimarlık/inşaat/tasarım (m/i/t) bölümlerinin en az birinde öğrenci, 13’ü (\%26) mimarlık/inşaat/tasarım sektörlerinde çalışan, geriye kalan 13'ü (\%26) öğretmen, doktor ve mühendislerden oluşan diğer meslek gruplarındandır. Görsel etki değerlendirme ifadelerinin meslek gruplarına göre ciddi farklılıklar göstermekte olduğu görülmektedir. Çok fazla faktör içinde farklılık söz konusu olduğu için ortak olanlar; genel değerlendirme faktörlerinde uyumlu, biçimsel faktörlerde kapalı, ölçeksel faktörlerde yüksek, etkisel faktörlerde belirgin olarak değerlendirilmektedir (Şekil 7). Buna göre çalışma alanının çevresindeki yapılarla birlikte;

genel değerlendirmesi;

- $\mathrm{m} / \mathrm{i} / \mathrm{t}$ sektöründe çalışanlara göre hoş, uyumlu ve olumlu;

- $\mathrm{m} / \mathrm{i} / \mathrm{t}$ bölümlerinde okuyanlara göre hoş, uyumlu, oldukça fazla olumlu;

- diğer meslek gruplarındakilere göre ise oldukça fazla hoş, oldukça fazla uyumlu ve kesinlikle olumlu bulunmuştur.

> kütlesel değerlendirmesi;

- $\mathrm{m} / \mathrm{i} / \mathrm{t}$ sektöründeki çalışanlara göre oldukça fazla güçlü ve kaba,

- $\mathrm{m} / \mathrm{i} / \mathrm{t}$ bölümlerinde okuyanlara göre güçlü ve kaba,

- diğer meslek gruplarındakilere göre ise oldukça az güçlü ve oldukça az kaba olarak bulunmuştur.

$>$ biçimsel değerlendirmesi;

- $\mathrm{m} / \mathrm{i} / \mathrm{t}$ sektöründe çalışanlara göre karmaşık, oldukça fazla kapalı ve tekdüze, 
- $\mathrm{m} / \mathrm{i} / \mathrm{t}$ bölümünde okuyanlara göre oldukça fazla karmaşık, kapalı ve oldukça az tekdüze,

- diğer meslek gruplarındakilere göre ise oldukça az karmaşık, oldukça fazla kapalı ve oldukça az oranda tekdüze bulunmuştur.

> diş cephede kullanılan yüzey elemanlarının uyum değerlendirmesi;

- $\mathrm{m} / \mathrm{i} / \mathrm{t}$ sektöründe çalışanlara ve $\mathrm{m} / \mathrm{i} / \mathrm{t}$ bölümlerinde okuyanlara göre malzemesi ve rengi uygun,

- diğer meslek gruplarındakilere göre ise malzemesi oldukça fazla oranda uygun, rengi uygun olarak bulunmuştur.

ölçeği bakımından değerlendirmesi;

- $\mathrm{m} / \mathrm{i} / \mathrm{t}$ sektöründe çalışanlar, $\mathrm{m} / \mathrm{i} / \mathrm{t}$ bölümlerinde okuyanlar ve diğer meslek gruplarındakilere göre oldukça fazla geniş (iri) ve oldukça fazla yüksek bulunmuştur.

etki değerlendirmesi;

- $\mathrm{m} / \mathrm{i} / \mathrm{t}$ sektöründe çalışanlara göre oldukça fazla ilginç, yeni ve modern,

- $\mathrm{m} / \mathrm{i} / \mathrm{t}$ bölümünde okuyanlar ve diğer meslek gruplarındakilere göre kesinlikle ilginç ve kesinlikle yeni ve modern

- bütün meslek gruplarındakilere göre ise kesinlikle belirgin bulunmuştur.

\section{Sonuç}

Bu çalışmada; Eskişehir tarihi kent dokusu içinde inşa edilmiş ve sürdürülebilir bakış açısı ile uluslararası üne sahip yabancı mimarlar tarafından tasarlanmış kültürel bir modern bina örneklem alanı olarak seçilmiştir. Araştırma kapsamında yeni yapının görsel etki değerlendirmesinin farklı kullanıcı gruplarına göre yanıtlanan anketler üzerinden analiz edilerek verilerin saptanılması sağlanmıştır.

Odunpazarı Modern Müze binasının görsel etki değerlendirmesinde cinsiyet gruplarına göre yapılan genel değerlendirmede ciddi farklar olmadığı görülmektedir. Yaş grupları arasında ise; biçimsel, doku ve yüzey elemanlarına ait faktörlerde küçük de olsa farklılaşmalar yaşandığı anlaşılmaktadır. En ciddi farklılıklar mimarlık/inşaat/tasarım sektöründe çalışanlar, bu sektörlere ait bölümlerde okuyanlar ve bu sektörlerde çalışmayan diğer meslek grupları arasında görülmektedir. 
Diğer meslek gruplarında olan katılımcılar yeni yapıyı belirgin oranda hoş, uyumlu ve olumlu değerlendirmekte, biçimsel olarak kesinlikle karmaşık bulmamakta, doku ve yüzey elemanlarına ait faktörlerde de malzemesini çevresine göre uygun bulmakta oluşları ile mimarlık/inşaat/tasarım sektöründe çalışan ve bu bölümlerde okuyan öğrencilere göre oransal ölçüde ayrışmaktadır. Mimarlık/inşaat/tasarım sektöründe çalışanlar, diğer meslek gruplarına göre yapıyı belirgin oranda kaba, geniş, tekdüze bulmakta, malzeme ve renk uyumları açısından çevresine göre uygun bulmamaktadır. Mimarlık/inşaat/tasarım bölümlerinde okuyanların görsel etki değerlendirmesindeki genel eğilimi ise bu sektörde çalışanlar ile ufak farklılıklar içerse de genel olarak paralellik göstermekte olduğu anlaşılmaktadır. Mimarlık/inşaat/tasarım sektöründe okuyan/çalışanların yapıyı diğer meslek gruplarındakilere göre daha olumsuz nitelemesinde, bir binanın görsel etki değerlendirmesinde önemli olacak kütlesel, biçimsel ve dış cephe yüzey elemanlarının uyumu gibi değişkenlere yönelik daha dikkatli incelemeler ortaya koymuş oldukları çıkarımı yapılabilir.

Anket içinde açık uçlu olarak bırakılan sorulara verilen yanıtlar değerlendirildiğinde ise binanın modern tasarımı genel olarak beğenilmekte; ancak kent ile ilişkisi konusunda net bir yanit verilemeyip projelendirme aşamasından önce halk katılımını özendiren atölye çalışmaları benzeri etkinliklerin yapılması önerilmektedir.

Yapının çevre ile ilişkisinin özgün olup olmadığı sorusuna verilen ağırlıklı yanıt, binanın tek başına orijinal ve ilginç bir stile sahip olduğu; ancak çevre ile uyumu konusunda katılımcların çekimser kaldığı anlaşılmaktadır. Bunun sebebi, binanın ölçeksel olarak fazla geniş (iri) ve yüksek bulunması ile açıklanabilir. Ayrıca, yapının modern ve yeni olarak belirgin bir şekilde ifade edilen görsel etkisinin kent kimliği ile uyum içinde olmadığı, açı uçlu sorulara verilen yanıtlarla saptanmaktadır. Bunun gerekçeleri olarak da, biçimsel ve ölçeksel temelde çevre yapılarla uyumu konusunda oldukça az oranda uygun bulunması gösterilebilmektedir.

Müze binasının, sektörel ve ana akım medya platformlarında sıklıkla haber konusu olmasının sebeplerini öğrenmek üzerine ankete eklenen sorulara verilen yanıtlarda, mimari tasarım ekibinin ünlü bir yabancı firma olmasının etkili olduğu yönünde görüş belirtilmiştir. Çağdaş yapının tarihi çevre dokusu içinde inşa edilmesinin de güçlü bir popülarite unsuru olabileceği katılımcıların çoğunluğu tarafından ifade edilmiştir.

Bu çalışma ile tarihsel kent dokusu içinde projelendirilmiş yeni bir kültürel yapının, bulunduğu çevredeki görsel etkisinin Norberg-Schulz'un 
doğa, insan ve yapı arasındaki ilişkiye getirmiş olduğu "Genius Loci" yerin ruhu- öğretisi bağlamında değerlendirilmesinin önemi konusunda ilerisi için yol gösterici olabilecek ipuçları ortaya konmaktadır. Görsel etki değerlendirilmesinin incelendiği bu çalışmanın devamı niteliğindeki araştırmalar, iç mekân kurgusu ve karşılaştırmalı olarak başka çalışma alanları ile incelenmesini kapsayabilecek şekilde genişletilebilir. Böylelikle; hem görsel-işlevsel hem de kent kimliği ve sosyal hayat ile ilişkili psikocoğrafik çevredeki etki çözümlemesi üzerine literatüre katkı sağlayabilecek araştırmalar ortaya konulmuş olacaktır. 


\title{
Extended Abstract
}

\section{Visual Impact Evaluation of a Contemporary Building in a Historical Pattern: Odunpazarı Modern Museum Sampling Area}

\author{
Gözde Kızılkan \\ ORCID: 0000-0002-9042-4696
}

Perceiving, knowing, and interpreting the environment are realized through the sense organs. The sensations that an individual receives from the environment are mainly effectuated upon visual stimuli. The visuality of the physical space is shaped by the facts expressed through principles such as harmony, repetition, rhythm, hierarchy, solid-void, as well as the features of aesthetic elements such as texture, color, and shape. In this context, the visual impact is revealed by measuring all these distinctive qualities through evaluation studies.

The whole process of sorting, deciding, and applying the choices are attained upon defining the environmental qualities. It is the subject of many research studies and reveals forward-looking results that the visual features of the places described as pleasant, offer distinct and legible, semantically rich, and diverse environments. In many studies supported by expert opinions, it is structured that the aesthetic preferences in the physical environment are shaped by the socio-demographic and cultural effects. In the inquiries made with users under certain conceptual frameworks (comfort level, satisfaction level, perception utility etc.), it is proven that various age groups, occupational groups, education levels, and socio-demographic characteristics play an important role in the differentiability of the visual impact evaluation factors. There have been various research and studies done so far which show that the preferences of architects/planners/designers on visual impact evaluation differ significantly from those who do not have professional training in these areas.

Historical urban fabric consists the places of memory that reflect the physical and socio-cultural structures, lifestyles, and human-environment relations of the past periods. Therefore, these special areas that shape the urban memory should be handled in a holistic manner with conscious and harmonious designs, functions, and evaluation processes. Opinions on historical urban fabric interventions that are un/successful are often expressed by experts; however, 
whether similar views are valid for non-expert users brings different research questions to mind.

This study focuses on the visual impact evaluation of a contemporary cultural building in a historical urban pattern. A survey was conducted with 50 participants who visited the sampling area. The data collection on the participants' views were based on their gender, age, and occupation. In this context, the research question is to determine and interpret the visual impact factors of a modern building in a historical urban fabric upon the individuals' different socio-demographic characteristics. The architectural stimulus chosen as the field of study gives direction to the design and architecture community in both local and national mediums. The aim of the study is to measure how a contemporary cultural building, designed by an international architectural firm in a historical urban pattern, is interpreted by its users and to evaluate the visual impact of the building by the individuals that are working / studying in the architecture/construction/design sectors and other occupational groups.

In order to measure the semantic responses to the environment with the help of the question-answer system used in the method of this survey, a 5-range question-answer structure, which is similar to semantic differentiation and semantic ranking techniques, has been constructed. The system was adapted from the methods in Bishop's (1977) CRIG Analysis and Polatoğlu's (1994) experimental study. Factor groups were used to develop evaluations to measure the approaches to the visual environment. Factor groups are categorized and detailed as follows: General Assessment (pleasant, harmonious, positive), Mass (strong, bulky), Form (complex, closed, monotonous), Exterior Surface/Texture (material compatibility, color compatibility), Scale (large, high), Effect (interesting, new, distinct).

The field of study is in Eskişehir and the basis of its urban development is Odunpazar1 district built on a hill in the south of the city. The district is one of the rare and protected areas that has survived until today with its Ottoman civil architectural structures and wooden houses. Historical Odunpazarı Houses are settled in harmony with the geographical position of the street and the land in accordance with the topographic structure of the region. Although Odunpazar1 is an old settlement, the urban areas used today gained function as the central region in the periods after the declaration of the republic and a new transformation understanding was adopted with the modernization movements.

Opened in September 2019 in Eskişehir's Odunpazarı district, Odunpazarı Modern Museum (OMM) is in the developing central region of the city. It was 
designed by Japanese architect Kengo Kuma and his team, planning to encourage an intercultural interaction intertwined with the historical area where the traditional Ottoman wooden residential dwellings that are entitled to enter the UNESCO World Cultural Heritage Temporary List are clustered. It can be observed that the building provides a versatile experience for its users, both due to its design process and actors, its integration with the historical immediate surrounding and the contemporary artworks displayed in its interiors.

To measure the visual impact evaluation of the new and contemporary cultural building in a historical pattern, users with different socio-demographic characteristics who visited the sampling area were participated in the survey. It is seen that there are no significant differences in the general evaluation according to gender groups. Among the age groups, it is understood that there is a slight differentiation in the factors of form, texture, and surface elements. The most distinctive differences are seen between those who work or study in the architectural/construction/design sector and other occupational groups. It can be inferred that those who work or study in the architecture/construction/design sector describe the building more unfavorably than those in other professions, since they could have revealed more careful observations into factors such as the compatibility of mass, form and exterior surface elements that are substantial in the visual impact evaluation of a building. With this survey, it has made a way forward about the important visual factors of evaluating a new cultural building located in a historical urban pattern in the context of the doctrine of the Genius Loci which Norberg-Schulz has brought to the relationship between nature, human and structure.

\section{Kaynakça/References}

Aksoy, E. (1975). Mimarlıkta tasarım, iletim ve denetim. K.T.Ü. Yayınları. İstanbul: Gün Matbaasi.

Aydınlı, S. (1992). Mimarlıkta görsel analiz. İstanbul: İTÜ Mimarlık Fakültesi.

Bishop, J. (1977). CRIG Analysis. Bulletin of Environmental Education, 73, 3-8.

Darçın, P. (2012). Saint Antoine Kilisesi döşeme kaplaması deseninin kullanıcı beğenisi yönünden incelenmesi. Ç. Polatoğlu (Der.) Mimarlıkta Görsel Etki Değerlendirme Yöntem ve Teknikleri içinde (s. 114-132). YTÜ.MF.DK-2012.0860. İstanbul: Yıldız Teknik Üniversitesi Basım Yayın Merkezi.

Designboom (2019, 14 Aralık). Kengo Kuma's Odunpazari Modern Museum in Turkey to open in June. https://www.designboom.com/architecture/kengo-kumaodunpazari-modern-museum-turkey-opens-03-15-2019/ adresinden erişilmiştir. 
Düzgün Bekdaş, H. ve Yıldız, S. (2018). Tasarım ve sanat arakesitinde kavramsal düşünme: Enformel eğitim çalışmaları (2009-2015). Megaron, 13(2), 324-333.

Groat, L. N. ve Wang, D. (2013). Architectural research methods (2. ed.). New Jersey: John Wiley \& Sons.

Hershberger, R., ve Cass, R. (1988). Predicting user responses to buildings. J. Nasar (Ed.), Environmental Aesthetics: Theory, Research, and Application içinde (s. 195211). Cambridge: Cambridge.

Janssens, J. (1984). Looking of buildings individual variations in the perception of building exteriors. Lund: Lund Institute of Technology.

Krampen, M., Öztürk, K., Özek, V., ve Saltık, H. (1978). Eski ve yeni görünüşlerin öznel izlenimleri ve nesnel ölçümü. Trabzon: KTÜ.

Küller, R., (1973). Beyond semantic measurement. Architectural Psychology içinde (s. 181-197). Lund: Studentlitteratur AB.

Lozano, E. (1988). Visual needs in urban environments and physical planning. J. Nasar (Ed.), Environmental Aesthetics: Theory, Research, and Application içinde (s. 395421). Cambridge: Cambridge.

Nasar, J. L. (1989). Symbolic meanings of house styles. Environment and Behavior, 21(3), 235-257.

Osgood, C. E., Suci, G. J., ve Tannenbaum, P. H. (1975). The measurement of meaning $(9$. ed.). Chicago: University of Illinois Press.

Özcan, K. (2009). Sürdürülebilir kentsel korumanın olabilirliği üzerine bir yaklaşım önerisi: Konya Tarihi kent merkezi örneği. METU JFA, 26(2), 1-18.

Palmer, J. F. (2000). Reliability of rating visible landscape qualities. Landscape Journal, 19(1-2), 166-178.

Polatoğlu, Ç. (1994). Yeni yapı tasarımlarının görsel etkilerinin araştırılması. Ç. Polatoğlu (Der.) Mimarlikta Görsel Etki Değerlendirme Yöntem ve Teknikleri içinde (s. 82-98). YTÜ.MF.DK-2012.0860. İstanbul: Yıldız Teknik Üniversitesi Basım Yayın Merkezi.

Polatoğlu, Ç. (Der.). (2012). Mimarlıkta görsel etki değerlendirme yöntem ve teknikleri. YTÜ.MF.DK-2012.0860. İstanbul: Yıldız Teknik Üniversitesi Basım Yayın Merkezi.

Rapoport, A. (1982). The meaning of the built environment. California: Sage Publications. Rasmussen, S. (1994). Yaşanan mimari. (Ö., Erduran, Çev.). İstanbul: Remzi Kitabevi.

Sanoff, H. (1974). Measuring attributes of the visual environment. Designing for Human Behavior: Architecture and the Behavioral Sciences, 244-260.

Sanoff, H. (1991). Visual research methods in design. New York: Van Nostrand Reinhold.

Smardon, R. C., Palmer, J. F., ve Felleman, J. P. (Eds.) (1986). Foundations for visual project analysis. New York: Wiley.

Sorte, G., J. (1975). Methods for presenting planned environment. Man-Environment Systems, 5(3), 148-154.

Zeisel, J. (1995). Inquiry by design, tools for environment and behavior research. Cambridge: Cambridge University Press. 